\title{
FAMILY BUSINESS ENTREPRENEURSHIP IN TOURISM AND HOSPITALITY INDUSTRY - A STUDY ON THE PONDICHERRY PERSPECTIVE OF MANAGEMENT
}

M. Kanthan*, G. Anjaneyaswamy**

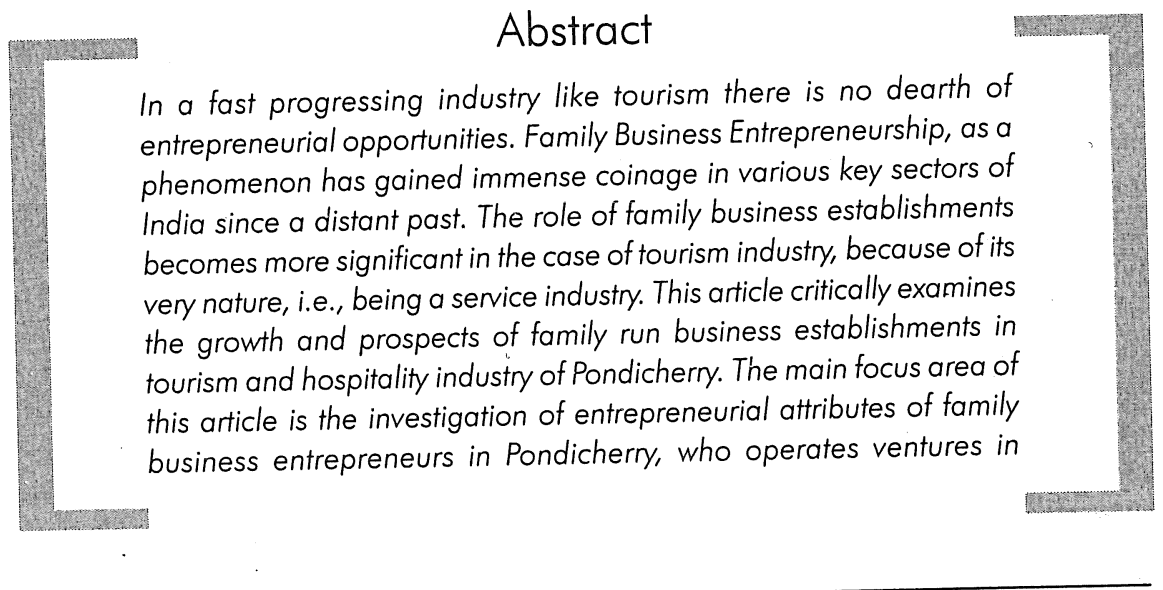

* Ph.D Scholar, Dept. of Tourism Studies, Pondicherry University, Puducherry.

** Professor and Head, Dept of Tourism Studies, Pondicherry University, Puducherry. 


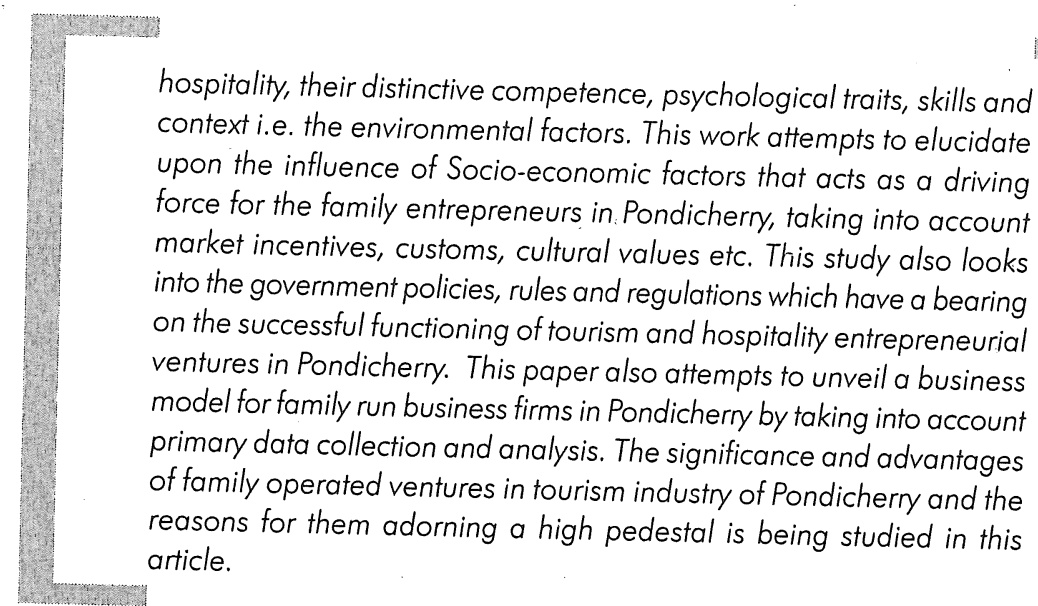

\section{Introduction}

Despite the fact that business planning can stimulate growth of enterprises, there is still a lack of research focusing on planning processes in family business. The following article presents a survey family business in strategies of Pondicherry tourism and hospitality industry and investigates their planning and strategic development behavior. As the business environment is becoming increasingly more complex, accompanied by intensified competition, rapid advances in technology and most critically, rising churn, be it customer or employees, there is an unprecedented rise in corporate failures today. And, just as amazing as the increasing number of failures, the fact is that most of the companies that attempt a recovery, also fail. Against this backdrop, it makes sense for companies to understand the reasons for their decline, in their performances, and find ways to avoid a potential bankruptcy situation. However, sickness is not restricted to corporate only. The same factors that cause sickness in corporate, are also reasons for sickness in small and medium sized businesses. However, the gravity of the factors may vary and it would be pertinent to say that the study of failure and turnaround for small and medium business should be separately considered as the rules of the game for the large corporate houses need not necessarily be the same for the small and medium sized entrepreneurs The Hotel business or the Restaurant business is one category which deserves special interest. The family business restaurant industry category contributes substantially to the GDP of the country. The entrepreneur plays in the successful turnaround of ailing restaurants and tourism business. This article aims to study the various strategies that have been used by the hotel sector family businesses. 
The successful family business enhances community development, create new jobs, and provide a better quality of life for the residents. They attract new business and residents to these areas. Family business will undoubtedly continue to survive in a new vein in the future.

This article examines the factors that have enabled the owners of tourism and hospitality business to become successful entrepreneurs and the difficulties that were encountered by these businesses while getting started and the changes that occurred as these firms grew bigger. External environmental factors, such as socioeconomic, political and financial are examined to evaluate the impact of the environmental aspects on entrepreneurial growth and development. The article identifies the problems faced by these firms during their four stages of development and operational growth.

In the accommodation sector, the Government of Pondicherry permitted private citizens to operate hotels and inns. Joint venture investment in high quality accommodation was also allowed. Foreign investment in the tourism industry was particularly notable in the hotel sector where international chains began supporting new construction and buying in to existing capacity. Family businesses within the tourism and hospitality industry have developed in all parts of the Pondicherry economy. This sector started as a simple relatively low skilled segment of the market that offered accommodation and related services to domestic travelers. Today tourism and hospitality is one of the fastest growing industries particularly in Pondicherry. It has benefited from people wanting to escape their everyday routine to engage in both domestic and international vacations. This growing trend towards involvement/ participation in travel and tourism also has resulted the increasing number of foreign tourists.

\section{An Overview of Pondicherry Tourism Entrepreneurship}

French dreams of an Indian empire began and ended in Pondicherry. But in the scattered territories of the Union Territory of Pondicherry there remains, what little there is the best of the French influence in India. And that makes the territory, especially its headquarters, Pondicherry, unique, something quite different from rest of India. The French connection, the serene atmosphere of urban Pondicherry influenced by the Aurobindo Ashram and the beach combine to make Pondicherry a fascinating destination.

The Union Territory of Pondicherry comprises tour enclaves in three South Indian States and includes the seaside towns of Pondicherry and Karaikal in Tamilnadu, Yanam in Andhra Pradesh and Mahe in Kerala. The former French colony is now 
very much Indian, but traces of French influence in Puduchery, as it is called today, linger in the policeman's re kepis, spellings on signboards, in some of the buildings and stones, the accented Tamil, English and French that can still be heard, and in skillfully planned township with streets aligned at right angles - a legacy of the
French planners.

In the tourism industry, dynamic entrepreneurs are needed who can visualize opportunities for new development and also devise creative ways of managing the existing supply components. The ability to foresee the opportunity along with location pool in the financial support, selection of ideal location/site and subsequently to engage designers to create physical settings, and gather the human resources needed to effectively manage the infrastructure and services which is utmost important for tourist development. For industrial nations, entrepreneurship is an intrinsic phenomenon. But for the developing and undeveloped countries entrepreneurial attributes of the people has not yet fully bloomed, and hence might handicap the solicit development aspects in the Tourism and Travel industry.

In developing economies like India where opportunities are unlimited, economic progress has to be brought along with social justice. Entrepreneurs play a vital role as innovators infusing new ideals into the economy and thereby stimulating it. Tourism opens doors for entrepreneurship especially in places like Pondicherry which is an exotic destination charmed with confluence of Indian and French cultural symbols. The potential for tourism development in Puducherry revolves around the entrepreneurs, who offer new products and quality services to the tourists. The entrepreneurs based in Puducherry primarily reach out the facilities and experiences to guests in an effective manner. The incredible tourist influx to Puducherry indicates that tourism is becoming a vital engine for economic growth of Puducherry. The entrepreneurs based in Puducherry has immense opportunities to utilize the emerging trends of tourism and can also innovate new tourism products which surely will strengthen the state of affairs of tourism promotion in Puducherry.

Major projects like water sports and theme parks, world class indoor stadium, adventure sports facilities, amusement parks of high standards, quality convention centers etc are yet to arrive in Pondicherry. This speaks volumes of the existing gap between demand and supply in the area of entrepreneurship in tourism.

Tourism in Pondicherry is one of the oldest and most successful industries. Pondicherry government has initiated overall planning and execution of schemes for the development, upgradation and improvement of tourism infrastructure in different parts of state. Government has also stressed for greater devolution of power at the local levels. All these steps are likely to pay rich dividends in the coming years for 
investments in theme based projects in the state. Given the huge potential of this sector in Pondicherry, while making efforts towards the growth of tourism and scaling up of incentives; there is also the need to ensure that this growth is geared towards citizen empowerment and commercial and ecological sustainability. The mysticism and cultural heritage of Pondicherry has attracted travelers and tourists across the entire world over the centuries. It is endowed with diverse array of scenic, cultural, culinary and leisure avenues.

\section{Opportunities for Entrepreneurs in Tourism Industry}

Excellent opportunities exists for entrepreneurs in the accommodation sector of the industry - especially in the development and operation of camping grounds, caravans parks, game parks, holiday camps, hotels, motels, bed-and-breakfast establishment and guest houses. Guest houses and Bed-and-breakfast establishments in particular have become very popular. Opportunities in transport for the potential entrepreneurs are mostly in terms of taxis, car hire, boat trips and bus services. An entrepreneur can package tours and then make use of other entrepreneurs for rendering support services such as transportation. There are opportunities in the development of man-made attractions, e.g. monuments, theme parks, waterfront development, parks, reserves, arts and crafts galleries and cultural tourism, which includes cultural villages. Support services, such as catering, tour guides, marketing and training, could also offer good opportunities for entrepreneurs. The field of entertainment, restaurants, coffee shops, tea gardens, acting, traditional dancing and music represent only a few of the opportunities.

\section{Successful Business Leadership}

Entrepreneurs and business leaders are at the heart of the tourism industry. They can read the market lead and manage change, adopt and reinvent existing business and setup ventures too. In tourism industry where the total visitor experience counts, customer focus will increasingly call for leadership that promotes collaboration across tourism and tourism related businesses.

\section{Model and Conceptual Framework}

The conceptual framework represents an integrated framework of 'entrepreneurial environment' that includes four external variables of four different stages of the firm's growth and development. Each of the four elements of new venture creation is connected to build a specific entrepreneurial environment and used to examine 
the environmental conditions that include political environment, financial environment, and socio economic environment. This approach allows measuring various problems that tourism and hospitality business face during their four stages of development and growth. This model holds good in its scope because it examines the perception of external variables of the entrepreneurial firm development without examining the management expertise and the competencies necessary for the successful growth and development of an entrepreneurship firm. Despite this limitation, its theoretical framework can be used to examine the process of entrepreneurial development and the progress of economic reforms from central planning to a market economy.

\section{Research Methodology}

A questionnaire was developed and pre-tested that served as the primary data gathering device. The study area remained in and around Pondicherry. The high concentration of entrepreneurs was in small family oriented business. Majority of the entrepreneurs owned family business, particularly in hotel and tourism sector. The data was collected by interviewing 50 family business entrepreneurs. All family businesses included in this study operate at the last stage of the firm's growth and development. The study focused on premier hotels and travel agencies of Pondicherry. The problem faced by the entrepreneurs at every stage was also ascertained.

\section{Empirical Findings}

The increasing interest and demand for tourism and hospitality pushed many families into the development of small family business to meet the needs of increasing tourism and hospitality industries. The businesses included in this study represent the following activities: in the family owned and operated hotels (22\%), Coffee shops and restaurants (27\%), bed \&breakfast establishments (14\%), transportation (11\%), and Souvenir shops (10\%).

According to the survey results, the respondents were found to be well educated with good technical and engineering skills. Forty percent had obtained university degree, fifty five percent had a technical degree or diploma and three percent had a high school or lesser education. Thirty seven percent of proprietors had former business training or experience, twenty seven percent had family training, and thitty six percent were self-trained. Most of the respondents had many years of working experience in managerial positions at state-owned enterprises. 
Family business development in Pondicherry has been hindered by lack of preferential treatment, high taxation and the lack of low-cost, long-term financing to improve the entrepreneurial process. The findings of the study call for:

1) Family business be given opportunities for low cost borrowing capital funds

2) Technical support and access to technology should be made a priority for small business development

3) More entrepreneurial and business training programs should be made available

4) The government should offer tax incentives and other special programs for small business and should reduce reporting requirements; and

5) Financial and regulatory institutions in Government should create a more enterprise-friendly culture that supports entrepreneurs not only financially but also through networks training, and business information systems.

The majority of businesses surveyed are small operations and $45 \%$ of the firms have less than 10 employees, $42 \%$ have 10 to 30 employees and $13 \%$ have more than 30 employees. The study brought to light the fact that the primary reason for starting a business was to supplement family income. The primary source of financing is personal savings ( $80 \%)$. Borrowing from friends and family $(42 \%)$ is a secondary source of capital for development and growth. Some of the savings came from speculative trading profits associated with rents. Due to the limited financing options for start-up capital, many family business owners maintained full-time employment to support their business. Only a few family businesses $(5 \%)$ received bank loans. $95 \%$ of entrepreneurs interviewed spent an average of 50 hours per week on working. They also found it hard to sustain this level of commitment for the growth of their family businesses. They stated that possessing a high energy level allows them to complete their goals and achieve target. They like to set ambitious targets that challenge them. $99 \%$ of the respondents believed that they have control over their life and are prepared to take the future into their own hands; they believe that they have to make things happen by themselves. All respondents stated that they were good at making decisions in an uncertain and ambiguous environment. They were able to tolerate ambiguity and stick to fundamental issues. They also stated that their business had to operate with constraints on financial resources, lack of suitably trained staff and a shorter perspective imposed by operating in a transitional economy. These family business entrepreneurs opined that confidence in one's ability as a businessperson, one's propensity for risk taking and valuing new ways of doing things appear to enhance innovative behavior. New services and products are more likely to be provided when owners are more confident about their values. 
The family business entrepreneurs studied, also shared several other personality traits and personal experiences which seem to have affected and moulded their nature. Individuals who started their own business have an optimistic, positive attitude about the present and the future; they seldom dwell on the past. They often expressed that they might sell their current business in order to start another one that is more personally fulfilling and economically successful.

\section{Political Environment}

Small family businesses were asked to state their level of satisfaction identified as the political and legal environment that could affect their activities at different stages of their growth. Low levels of satisfaction at all stages were reported on four items, credit terms, transaction burdens, law and regulations, and the taxation system. Respondents stated that there are no longer any problems with property rights that could lead to high costs of conducting business. The risk of property loss is no longer a substantial entry barrier for prospective small entrepreneurs and potential outside investors in new ventures.

\section{Financial Problems}

The availability of financial resources can be a major factor of the frequency of business start-ups. Many lenders are unwilling to invest in high risk projects or tend to withhold support until the firm has been established successfully. Respondents expressed dissatisfaction with access to capital, financial assistance, and institutional barriers including collateral requirements, lack of information regarding financing options, problems of sourcing local capital, problems of perceived financial expertise, lender familiarity with small business, resources to pursue financing and problems relating to lenders interest in family business at all four stages of growth and development. Most entrepreneurs see financial limitations as a main barrier to growth. The lack of a well-developed modern commercial banking system is one of the biggest obstacles to the success of economic reform. According to respondents, their family business development would have been more rapid if respondents could borrow. Most family firms had only a small amount of its own fixed capital, and most of the money was tied up as working capital. This problem has declined in importance over the years as the private sector developed its accumulated capital. Access to financial assistance unfamiliarity of lenders, and excessive collateral systems are problems at all stages of growth, but these problems have not been as acute in later stages as in the earlier stages of the firms' growth and development. Access to capital and financial information, problems with availability of resources, and concerns about foreign trade are important impediments for expansion. 


\section{Socio-economic conditions}

There exists no common definition for a family business. While the majority of authors build on variables such as ownership participation, a much broader definition that includes social aspects of entrepreneurial life. Wherever family systems strongly interact with the entrepreneurial level of the enterprise system, the enterprise shows a family business character. Thus, the development of a family business depends on three factors, namely the entrepreneurs' family, ownership, and enterprise system. However, the relationship between the firm and the family does create a special entrepreneurial culture and philosophy which is unique for family business. Family businesses are based on human capital development and people realizing their dreams and developing their potential. The best people are the most highly skilled workers and managers who voluntarily left the public sector to start their own companies or to work for someone else. According to the respondents, there was no.significant impact of seasonality on tourism and hospitality industry on the performance of their business. The primary explanation for this is provided by the nature of tourism and tourism industry in Pondicherry. The tourism and hospitality industry in Pondicherry is young but offers tourist attractions throughout the year. The list of problems faced by the respondents included concerns about domestic state of the economy, exchange rates, labor costs, labor skills, taxes, access to foreign markets and domestic and foreign competition. The concern regarding the availability of skilled labor decreased as the number of reliable and qualified workers increased over time due to the increasing number of layoffs that pushed highly qualified workers into the private small business sector. These findings support the existing literature regarding organizational life-cycle and stages of development. They suggested that marketing and financial problems characterize the start-up stage while administrative, managerial, and strategic problems characterize the growth stage. They also suggested that the growth stage is more likely to be associated with problems related to management and organizational design.

\section{Advantages}

\section{Personal relationship with enterprise stakeholders}

For small enterprises, establishing personal relationship with customers and employees can be a main source of competitive differentiation. Business relations of small owner managers are often not based on contract but on personal relationships. This can lead to competitive advantages which are difficult to imitate but on the other hand personal relations can be a burden for the entrepreneurs. 


\section{Market niche advantages}

Technological developments, especially in the tourism industry, the market liberalization, as well as globalization opened up new opportunities for vital small and medium sized enterprises. Market niches, which are offen ignored by global and/or big enterprises offer growth chances for small family business. On one hand, small local business can easily identify lead customers' wishes, and on the other hand they should be able to maneuver new niche products for the upcoming new customer segments.

\section{Flexibility and reaction}

Due to a generally flat hierarchy in family businesses the management can decide quickly and react immediately to market changes.

\section{Continuity}

Particularly in Pondicherry the reputation of family business that have been operating for many years is in the eyes of the customer, a criterion for buying goods or services. The continuity of family business and their presence in the market place can be interpreted as strong social values.

\section{Family business do face a number of typical problems}

In the first growth phases family business face liquidity problems. Additionally while big enterprises act as anonymous and autonomous market suppliers, family business provide income for the whole family and its members often contribute below market performance.

\section{Family Employee}

On one side, family members whose labor market value is poor, cannot easily be made redundant. On the other side family entrepreneurs expect family members to have an extremely high motivation. Motivation systems or performance oriented incentive systems are thus not installed. Furthermore, it is not easy for small family business to attract and to finance qualified personnel from the labor market.

\section{Lack of planning or strategy development}

Theoretical literature contributions and empirical tourism industry studies suggest that most small family businesses neither keep written record of their future plans nor do they control their achievement following a strategic business plan. It becomes 
apparent that family evolution and enterprise development are two interrelated cycles which influence each other. Thus, strategic planning has to deal with both family life and enterprise life, while the latter includes business issues which can be found in every enterprise. In addition, the planning of succession is not common and is crucial for the long-term existence of family businesses.

\section{Conclusion}

The family businesses operating in Pondicherry have prevailed to be one of the key mechanisms in the economic transition. Economic reforms unleashed the potential for entrepreneurial development in a direction that assisted macro-economic stability and competitive market behavior. Although family businesses are still faced with many difficulties, this study found that these businesses continue to develop. Successful family business were found to be focusing on particular product or niche market, developing a strong competitive advantage offering high quality and superior service products. The chances for an entrepreneurial family business to survive and grow during the different stages of development are a functional barrier to operation that it is likely to encounter. The main problems encountered by family entrepreneurs in Pondicherry were from management expertise and limited business skills, the failure to control to or exploit community relationships, lack of sufficient financial resources, and limited marketing skills. Survey results do show dramatic changes from the first three stage of development to the stability stage. Despite the fact that majority of problems constraining entrepreneurs occurred during the first three stages, conception and development, commercialization, and growth, almost eighty-nine percent of firms managed to intensify their business activities and increase their growth.

This study found that in order to assure the future growth of family businesses the Pondicherry Government should adopt policies and regulations that provide a broader scope of opportunities. Economic policies that allow people to exercise their entrepreneurial talents and develop business skills should be encouraged. The government should address the needs for preferences, incentives, and lowcost and long term credit financing options. These measures will further accelerate family business development. Most important requirements are the offer of financial assistance to new family business creation are the development and establishment of incubator centers and industrial parks where resource facilities can be shared. This study provides tentative support for the contention that growth of family business proceeds in a stepwise fashion. Although further refinements of these problems are required, some of these information could be useful to agencies and institutions seeking ways to foster small family business growth. For example the need to improve financial expertise and to provide micro, mini-firm owners with financial information 
is necessary. Training agencies and financial institutions might focus on fiscal planning in programs aimed at small business start-ups. Alternative sources of capital, informal equity financing, venture capital, and leasing may be appropriate training topics for more established business owners who intend to expand. Pondicherry Government has done well in the macroeconomic management area that has been essential for the growth of the economy. The increasingly stable monetary environment will make it possible for the family business to grow and concentrate on productive rather then speculative investments. One vital lesson is that a transitional economy can do well by sticking to the fundamentals, macroeconomic stability, outward orientation, and sustained investment in physical infrastructure and primary education.

\section{References}

Donald F. Kuratoo, Harold P. Welsch (2001) Strategic Entrepreneurial Growth, London Harcourt College Publisher.

Clare E Williams and Eliza C. Y. Tse (1996) An Investigation of entrepreneurship in the Mature restaurant market, The International Hospitality Business, New York, Cassel Publication.

Mike Peters (2004) Business planning process in tourism family enterprises, Family Business Review, University of Innsbruck

Vasant Desai (2003) Small-Scale Industries and Entrepreneurship, Himalaya Publisher, New Delhi.

C.B. Gupta et al. (2001) Entrepreneurship Development in India, Sultan Chand Publisher, New Delhi.

Anu Chandran (2007) Tourism an overview, Kerala Tourism Academy, Thiruvananthanpuram.

G.S Sudha (2005) Management and Entrepreneurship Development, Indus Valley Publisher, Jaipur. 